\title{
External Fixator in Elderly Patients with Hip Fractures
}

Shilu Shrestha ${ }^{1}$, Bibek Banskota ${ }^{1}$, Tarun Rajbhandary ${ }^{l}$, Babukaji Shrestha ${ }^{l}$, Jwala Raj Pandeyl, Ashok Kumar Banskotal.

${ }^{1}$ Department of Orthopedics,B \& B Hospital, Kathmandu Nepal.

\begin{abstract}
Introduction: Fragility fractures around the hip are common in the elderly and are associated with significant morbidity and mortality. Early stabilization and mobilization reduces mortality associated with prolonged recumbence. In patients who are not fit for general anesthesia, external fixation under local anesthesia will help early mobilization.
\end{abstract}

Methods: A retrospective study of hip fractures treated between 2002 to 2009 was undertaken. Out of 242 hip fractures, 13 patients with inter-trochanteric fractures had undergone external fixator application under local anesthesia. There were 9 females and 4 males; five were on right side and 8 on left side. As per the system of American Society of Anesthesiologists (ASA), 10 were of grade III, 2 of grade IV and 1 of grade E. The age of the patient ranged from 60 to 92 years (average 80 years). The average delay in surgery was 8.2 days for cases presenting soon after the injury.

Results: Follow up was done at 6 weeks, 3 months and 6 months with the average follow up of 4.7 months. All the fractures $(n=13)$ united and the average time to radiological union was 3 months. Three patients had grade I pin tract infection which was easily controlled with local care. The average Harris hip score at final follow-up was 92.

Conclusion: External fixator can be a valuable tool for the treatment of hip fractures in high risk elderly patients with concomitant medical co-morbidities.

Keywords: external fixation; elderly; Hip fracture.

\section{ITRODUCTION}

A hip fracture is a debilitating injury in any age group. It is a very significant public health problem in the aging population contributing to considerable morbidity and mortality in this age group. According to one report, there were 1.66 million hip fractures worldwide in 1990 and this figure is projected to rise to 6.26 million by $2050^{1}$. Obviously, the cost implications of such a figure place huge demands on the health spending of any economy.

The mantra for the management of hip fracture is fixation of the fracture and mobilization as soon as possible. Currently the gold standard for fracture fixation is a dynamic hip screw. There is enough literature to prove that a delay in surgery in hip fracture is associated with an adverse outcome ${ }^{2}$. In situations where there may be anticipated delay in surgery, an external fixator applied under local anesthesia can be a valuable tool to reduce pain, maintain fracture reduction and encourage early ambulation $^{3,4}$.

Fragility fractures around the hip are common but challenging problems in the elderly who often have associated co-morbidities which increase the overall risks associated with open surgery. External fixation of these fractures under local anesthesia is an excellent option in their management allowing for early mobilization and thus reducing the complications associated with recumbency. the use of external fixator for these kind of fracture are not very popular in our country. the aim of this paper is to report the early results of extenal fixators in fragility fractures.

\section{METHODS}

A retrospective study of hip fractures treated at our center between 2002 to 2009 showed 242 cases out of which 13 were treated with external fixation. Inter-trochanteric fracture was the commonest accounting for $62 \%$ of all hip fractures. The most common type was Kyles type III. Mechanism of injury was domestic fall in almost $82 \%$ of the cases. Fracture fixation was done with dynamic hip screw in $81.4 \%, 8.6 \%$ were fixed with external fixator, $5 \%$ with dynamic condylar screw and in 5\% no intervention was done.

Of the 13 inter-trochanteric fractures who were treated with external fixator, 5 were on right side and 8 on left side. The age of the patients ranged from 60 to 92 years (average 80 years) of which 9 were female and 4 were male. Ten of these 13 patients were ASA (American Society of Anesthesiologists) grade III, 2 were grade

\section{Correspondence:}

\section{Dr. Shilu Shrestha}

Department of Orthopedics, B\&B Hospital, Gwarko,

Kathmandu Nepal.

Email: drshilu131@gmail.com 
IV and 1 was grade E. All cases were done under local anesthesia. The average delay in surgery was 8.2 days. One case presented to our center with a painful nonunion 7 months after sustaining an inter-trochanteric fracture. We managed the case with external fixator which was removed after 7 weeks and she is well mobilizing without pain in the hip.

All our 13 cases were done under local anesthesia with sedation due to co-morbid conditions precluding general or spinal anesthesia. $10 \mathrm{ml}(213 \mathrm{mg})$ of injection xylocaine with adrenaline (2\%) was diluted with $40 \mathrm{ml}$ of distilled water and injected on the fracture site and the pins site. We waited for about 10 minutes before inserting the pins. An image intensifier and fracture table was used. Following reduction, the fracture was stabilized with 2 or 3 schanz pins each proximal and distal to the fracture connected by a simple AO tubular rod.

The patients were made to sit up immediately postoperatively, graduating from bed to chair, chair to walker and limited non-weight bearing ambulation for up to 6 weeks after which gradual increase from toe-touch to
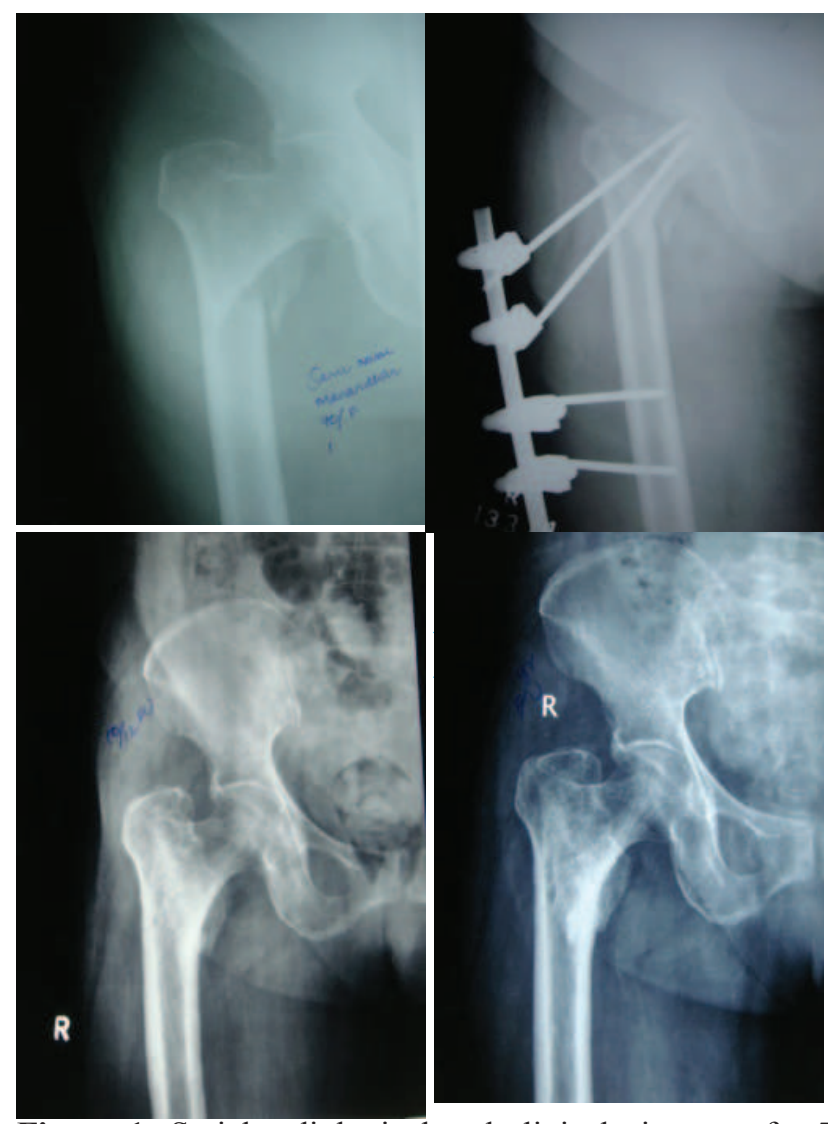

Figure 1: Serial radiological and clinical pictures of a 70 years old lady treated with external fixator. A-Pre-operative radiographic picture, B-Immediate post-operative $\mathrm{x}$-ray, C,D- X-rays at follow up 10 months and 1 year respectively. full weight bearing was instituted. Emphasis was given during the entire post-operative period to physiotherapy including chest physiotherapy and anti-thrombotic measures including daily prophylactic low molecular weight heparin and thromboembolic deterrent stockings. Patient's family was also educated for the physiotherapy and pin tract care so that they will continue so after discharge.

\section{RESULTS}

The average follow up was 4.7 months ranging from 3 months to 12 months. All fractures have radiological union at 3 months. Two patients had died 3 to 4 months post-operatively due to causes unrelated to external fixator application. The average Harris hip score at 6 months was 92. In three patients, collapse of the fracture into varus was noted but this did not cause any inconvenience with their activities of daily living. Three patients had grade I pin tract infection which were easily controlled with local dressing with normal saline. The average duration of hospital stay was 11.63 days (range 6 to 25 days).

\section{DISCUSSION}

Hip fracture is a leading cause of death and disability among the elderly ${ }^{6}$. Delay in operation is associated with an increased risk of morbidity and mortality ${ }^{2}$. The fundamental principle of management is thus aimed at early restoration of the anatomic alignment of the fracture, maintenance of the fracture reduction and early rehabilitation ${ }^{3}$. Although the sliding hip screw is the gold standard for fixation of these fractures, it may not always be possible to undertake this procedure in the face of major co-morbidities precluding general, spinal or regional anesthesia. In such circumstances, external fixation is a good alternative for fracture stabilization allowing for a quick, cheap and effective stabilization that can be undertaken under local anesthesia ${ }^{7}$. Some authors have even advocated an external fixator over a sliding hip screw in view of the shorter operative time, less blood loss, less pain and shorter duration of hospital stay ${ }^{4,8,9,10}$. Complications related to external fixator include pin tract infection which can easily be controlled with meticulous local care. Collapse of the fracture into varus is commonly found but this seems to be well tolerated by the elderly, possibly because of their low demands in activities of daily living or due to associated co-morbidities restricting excessive ambulation. In their study of 154 cases over an 8 year period, Dhal et al. noted an average union time of 16 weeks, good return to function in all cases, late displacement in 9 cases and deep pin track infection in $6^{11}$. 


\section{CONCLUSION}

In conclusion, External Fixator is useful in fixation of intertrochanteric fractures in elderly people with concomitant medical co-morbidities who are deemed unfit for general or spinal anesthesia. It can be carried out as a quick and safe procedure with minimal blood loss under local anesthesia, enabling the patients to ambulate early, thus, preventing or mitigating the problems associated with recumbence in the precarious scenario of a concomitant hip fracture.

\section{REFERENCES}

1. Kannus P, Parkkari J, Sievänen H, Heinonen A, Vuori I, Järvinen M. Epidemiology of hip fractures. International Bone and Mineral society. 1996;18(1):57-63.

2. Bottle A, Aylin P. Mortality associated with delay in operation after hip fracture: observational study. BMJ. 2006 Apr 22;332(7547):947-51.

3. Baumgaertner MR. The pertrochanteric external fixator reduced pain, hospital stay, and mechanical complications in comparison with the sliding hip screw. J Bone Joint Surg Am. 2002;84:1488.

4. Karn NK, Sing GK, Kumar P, Sherestha BP, Sing MP. Comparison between external fixation and sliding hip screw in the management of trochantric fractures offemur in Nepal. J Bone Joint Surg [Br]2006;88$B: 1347-50$
5. VallamshetlaVR and Thalava R. Effect of American society of anesthesiologists (ASA) grading on mortality, morbidity and functional outcome after hip fractures. JBJS-British Volume, Vol 88-B, Issue SUPP I, 43.

6. Christodoulou NA, Sdrenias CV. External fixation of select intertrochanteric fractures with single hip screw. Clin Orthop. 2000;381:204-11.

7. Rashid S, Dar G, Kangoo KA, Halwai MA: External fixation in the management of intertrochanteric fractures in elderly high risk patients. IJO 2008:8, 2

8. Moroni A, Faldini C, Pegreffi F, Kim AH, Vannini F, and Giannini S. Dynamic Hip Screw Compared with External Fixation for Treatment of Osteoporotic Pertrochanteric Fractures: A prospective, randomized study: J Bone Joint Surg Am. 2005 Apr;87(4):753-9.

9. Vossinakis IC, Badras LS: External fixator compared with Sliding hip screw for Pertrochanteric fractures of femur. J Bone Joint Surg [Br] 2002;84B:23-9.

10. Vossinakis IC, Badras LS: Management of Pertrochanteric fractures in high risk patients with an external fixation. Int Orthop 2001;25:219-22.

11. Dhal-A; Varghese-M; Bhasin-VB. External fixation of intertrochanteric fractures of the femur.J-Bone-JointSurg-Br. 1991 Nov; 73(6): 955-8. 